\title{
The Indian Journal of Gastroenterology: looking ahead at the next five years
}

\author{
B. S. Ramakrishna
}

Received: 2 July 2012 / Accepted: 2 July 2012 /Published online: 15 July 2012

(C) Indian Society of Gastroenterology 2012

The Indian Journal of Gastroenterology was launched 30 years ago, in 1982, as the official publication of the Indian Society of Gastroenterology and with Dr Bhupendra J Vakil as the Editor. Over the years, there have been different Editors at the helm including Dr F P Antia, Dr S R Naik and Dr Philip Abraham. The last 5 years, under the Chief Editorship of Dr Shobna Bhatia, has witnessed a major change in the nature and content of the Journal. The tie-up with Springer has been a landmark for the Journal making it more visible internationally. While the Journal continues to aim at its primary readership, i.e. the members of the Indian Society of Gastroenterology, medicine and science do not know any boundaries and the Journal will need to provide the evidence base and the review articles that will serve gastroenterologists in practice in India and internationally.

There has been a proliferation of Journals in the last decade and specialty journals such as the Indian Journal of Gastroenterology now have an increasing number of competitors. Journals will survive only so long as they reinvent themselves. In doing so, it is important to retain our core values while taking advantage of new technology to keep up with the times. The Journal belongs to the Indian Society of Gastroenterology and we wish to reach out to the members of the Society and hear their views on how we may improve the Journal. The space in the Journal is limited and thus we will need to be selective in our acceptance of manuscripts. In 2011, a total of 328 manuscripts were submitted, of which 210 originated from India. Our acceptance rate in that year was $32 \%$. As expected, manuscript rejection decisions were made fairly rapidly and the average time to a final decision of rejection was 44 days. On the other hand, acceptance decisions were often made after one to three revisions and hence the time to

\section{B. S. Ramakrishna $(\square)$}

Department of Medical Gastroenterology,

Christian Medical College,

Vellore 632 004, India

e-mail: rama@cmcvellore.ac.in final acceptance was 217 days. As the new Editor-in-Chief, it is my major priority to ensure that there is rapid review and decision on submitted manuscripts. Alongside this, the Editorial board and the publishers are committed to providing a more transparent review process and we are in continuous dialog with the publishers to provide tracking of the process on the website. Accepted manuscripts are usually published via Springer's Online Firstservice. They have a Digital Object Identifier (DOI) number and are citable in a few weeks after acceptance. The online publication date is accepted as the official date of publication. Being online makes these articles visible to the professional readership around the world, and the articles are downloadable for those who are interested in accessing them. In 2011, there were a total of 8,902 full-text downloads from the Journal's collection with Springer. Of the top ten downloads from the Journal, five were articles published in 2011, four in 2012 and one in 2009. Fifty-one percent of the download requests originated from the Asia Pacific, $26 \%$ from Europe and $19 \%$ from North America. About a half of the full-text article requests were from abstracting and indexing services. Table of Content alerts are sent out by email to interested readers.

It has been a pleasure and privilege to serve as Editor (Luminal Gastroenterology) for the last 5 years along with Dr Rakesh Aggarwal the Editor (Hepatology) and Dr Shobna Bhatia as the Editor-in-Chief. I would like to use this opportunity to acknowledge the many changes that were brought about in the Journal during Dr Bhatia's editorship. Mr Marian D'Souza has done a sterling job at the Journal's office in Mumbai and will continue to manage this office and remain involved from the time of manuscript submission through proof reading and uploading on to the online edition of the Journal. As the Journal moves forward we need to utilize to our best advantage the new paradigms continuously being invented to further communication in science and medicine. We hope that members of the Society and the readership of this Journal will be with us and constantly guide us along this journey. 